\title{
MODEL RAPID APPLICATION DEVELOPMENT DALAM PENGEMBANGAN SISTEM RESERVASI DAN PENYEWAAN KAMAR HOTEL
}

\author{
Sofiansyah Fadli \\ Teknik Informatika, STMIK Lombok \\ Jln. Basuki Rahmat No.105 Praya Lombok Tengah 83511 \\ sofiansyah182@gmail.com
}

\begin{abstract}
The development of computerized technology at this time greatly increased, almost in all business or business field utilizing computer technology as a medium of information to obtain information fast and accurate. The Queen Hotel is one of many existing hotels and has stood for the moment and has not utilized computer technology, especially in terms of reservation and hotel room rental to manage data and information for guests or visitors using services at the Queen Hotel.

One of the development of SDLC is Rapid Application Development (RAD) model which can also be used in system development by giving priority to time. In this study, the system designed and built applying the Rapid Application Development (RAD) model in which the design stage and workmanship of the system is relatively short around 60-90 days. This system is an effective media in the management of data reservasi (The data of the person who has reserved the room) and hotel room rental, facilitate officers in managing data in accordance with the part and position, facilitate the management of transaction data, reduce the level of unwanted errors and simplify the maintenance of data related to reservation transactions and hotel room rental.
\end{abstract}

Keywords: system development, RAD, Reservation System And Hotel Room Rental, SDLC.

\begin{abstract}
Abstrak
Perkembangan teknologi komputerisasi pada saat ini sangat meningkat, hampir disemua bidang usaha atau bisnis memanfaatkan teknologi komputer sebagai media informasi untuk memperoleh informasi yang cepat dan akurat. Hotel Queen merupakan salah satu dari banyak hotel yang ada dan telah berdiri pada saat ini dan belum memanfaatkan teknologi komputer, terutama dalam hal reservasi dan penyewaan kamar hotel untuk mengelola data dan pemberian informasi bagi tamu atau pengunjung yang memakai pelayanan jasa pada Hotel Queen.

Salah satu pengembangan SDLC yaitu model Rapid Application Development (RAD) yang juga dapat digunakan dalam pengembangan sistem dengan mengutamakan waktu. Dalam penelitian ini sistem yang dirancang dan dibangun menerapkan model Rapid Application Development (RAD) dimana dalam model ini tahapan perancangan dan pengerjaan sistem relatif singkat sekitar 60-90 hari. Sistem ini merupakan media yang efektif dalam pengelolaan data resrvasi dan penyewaan kamar hotel, mempermudah petugas dalam mengelola data sesuai dengan bagian dan jabatannya, mempermudah pengelolaan data transaksi, mengurangi tingkat kesalahan yang tidak dikehendaki dan mempermudah dalam pemeliharaan data-data yang berkaitan dengan transaksi reservasi dan penyewaan kamar hotel.
\end{abstract}

Kata kunci : Pengembangan Sistem, RAD, Reservasi dan Penyewaan Kamar Hotel, SDLC.

\section{Pendahuluan}

Perkembangan teknologi informasi saat ini berkembang begitu cepat tanpa mengenal waktu dan menjadi kebutuhan yang sangat mendasar bagi berbagai kalangan salah satunya yaitu perhotelan, berbagai aplikasi sistem informasi memungkinkan pemrosesan data dan laporan secara cepat dan akurat.

Hotel Queen merupakan salah satu dari banyak hotel yang ada dan telah berdiri pada saat ini $(\mathrm{SIUP}=\mathrm{N} 0.503 .42 / 693 / \mathrm{PRB} / 2012)$, dengan

ISSN. 2620-6900 (Online) 2620-6897 (Cetak) 
meningkatkan kinerja Hotel Queen ini terutama dalam hal reservasi dan penyewaan kamar hotel diharapkan dapat memberikan kemudahan pada pengurus hotel sehingga dalam proses reservasi dan penyewaan kamar hotel mendapatkan hasil yang benar. Sebagaimana kondisi sistem proses transaksi reservasi dan penyewaan kamar hotel yang berjalan pada Hotel Queen masih bersifat manual dimana semua dilakukan dengan cara di catat pada buku biasa, sehingga akan memungkinkan terjadinya suatu kesalahan dan data-data yang ada akan mudah hilang dan laporan yang dihasilkan masih kurang akurat.

Seiring dengan perkembangan teknologi yang mencakup dalam segala bidang kehidupan manusia maka hal ini juga dapat digunakan untuk membuat suatu sistem reservasi dan penyewaan kamar hotel di Hotel Queen yang berbasis komputerisasi. Tujuan dari penelitian ini adalah untuk menganalisis dan mengembangkan sistem reservasi dan penyewaan kamar hotel dengan menggunakan model RAD dan pendekatan terstruktur untuk menciptakan suatu rancangan dan aplikasi yang mudah difahami oleh pengguna terutama oleh petugas Front Office yang dapat membantu dalam pengolahan data transaksi dan data laporan. Sehingga sistem tersebut akan mempunyai nilai lebih dari pada sebuah sistem penyewaan dan reservasi kamar hotel yang dilakukan secara manual dan juga akan meghasilakan suatu sistem informasi yang efisien dan mempunyai produktifitas yang tinggi. Suatu sistem aplikasi yang terkomputerisasi akan memberikan dampak terhadap pengolahan data yang cepat dan tepat, dirancang secara otomatis dalam penginputan data-data transaksi dan data pelaporan.

\section{Tinjuan Pustaka}

\section{A. Penelitian Terkait}

Rimawati Ariani, dalam penelitianya mengambil judul Komputerasi Sistem Pengolahan Data Tamu Pada Hotel Purnama I Berbasis Client Server, penelitian ini membahas tentang proses pengolahan data tamu dengan metode analisis perancangan, dan pembuatan sistem informasis sistem pengolahan data tamu pada Hotel Purnama I berbasis Client Server menggunakan bahasa pemrograman Delphi 7.0 dan database menggunakan SQL Server 2005. Dengan tujuan membuat sistem informasi yang cepet, tepat dan akurat. Hasil dari penelitian tersebut adalah sistem informasi yang memudahkan dalam pengolahan data tamu pada Hotel Purnama I.

Pungud Kusbiantoro, dalam penelitian ini dijelaskan pada Hotel Bali Asri Pacitan masih menggunakan sistem manual. Dengan menggunakan sistem manual menimbulkan masalah seperti proses pembuatan laporan yang terlalu lama. Sehingga penulis mengusulkan suatu sistem yang memudahkan petugas dalam menginput, mengupdate serta mengontrol data. Dari penelitian yang dilakukan, dihasilkan program yang dapat memudahkan untuk pengolahan data pada Hotel Bali Asri Pacitan.

Sardiarinto, dkk., dalam penelitian ini membahas tentang rancang bangun sistem reservasi hotel menggunakan metode waterfall. Penelitian ini menghasilkan sistem informasi reservasi hotel. User merupakan petugas front office atau receptionist di hotel yang dapat melakukan transaksi antara lain booking, checkin, service room, service restaurant, checkout, dan melihat dan mencetak laporan sesuai kebutuhan.

Friska Dian Lolo Tandilian, dkk., penelitian ini membahas tentang rancang bangun sistem informasi reservasi hotel berbasis web dengan framework codeigniter, penelitian ini menghasilkan Penerapan Model View Controller pada Rancang Bangun Sistem Informasi Reservasi Hotel Berbasis Web Dengan Framework Codeigniter (Studi Kasus CV. BSB Travel) dapat berjalan dengan baik. Fungsifungsi yang ada pada sistem sudah sesuai dengan perancangannya. Dalam proses reservasi, pemesanan dapat berjalan dengan baik, dan dapat memberi keterangan yang cukup jelas bagi guest. Proses reservasi ini telah ditentukan oleh CV. BSB Tavel.

Safrian Aswati, Yessica Siagian, dalam penelitianya yang berjudul model rapid application development dalam rancang bangun sistem informasi pemasaran rumah, penelitian ini membahas tentang penerapan metode rad (rapid application development) dalam menghasilkan sistem informasi pemasaran rumah pada Perum Perumnas Cabang Sumatera Utara sudah dapat memberikan hasil yang maksimal. Secara signifikan sistem dapat memenuhi kebutuhan Perumnas dalam mengolah data konsumen dan pemasaran rumah serta dapat memenuhi kebutuhan konsumen dalam mendapatkan informasi pemasaran rumah.

\section{A. Hotel}

Hotel adalah salah satu jenis akomodasi yang mempergunakan sebagian atau keseluruhan bagian untuk jasa pelayanan penginapan, penyedia makanan dan minuman serta jasa lainnya bagi masyarakat umum yang dikelola secara komersil (Keputusan Menteri Parpostel no Km 94/HK103/MPPT 1987) 
B. Klasifikasi Hotel

Menurut keputusan direktorat Jendral Pariwisata, Pos dan Telekomunikasi No 22/U/VI/1978 Tanggal 12 Juni 1978 (Endar Sri, 1996), klasifikasi hotel dibedakan dengan menggunakan simbol bintang antara 1-5. Semakin banyak bintang yang dimiliki suatu hotel, semakin berkualitas hotel tersebut. Penilaian dilakukan selama 3 tahun sekali dengan tatacara serta penetapannya dilakukan oleh Direktorat Jendral Pariwisata.

\section{Data Flow Diagram (DFD)}

Merupakan diagram yang menggunakan notasinotasi untuk menggambarkan arus dari data sistem. DFD sering digunakan untuk menggambarkan suatu sitem yang telah ada atau sistem baru yang akan dikembangkan secara logika tanpa mempertimbangkan lingkungan fisik dimana data tersebut mengalir. Diagram Arus Data (data flow diagram) adalah gambaran grafis yang memperlihatkan aliran data dari sumbernya. Dalam objek kemudian melewati suatu proses yang menstransformasinya ke tujuan yang lain, yang ada pada objek lain (Fatta, 2007).

\section{Pengertian Sistem}

Sistem pada dasarnya adalah sekelompok unsur yang erat hubungannya satu dengan yang lain, yang berfungsi bersama-sama untuk mencapai tujuan tertentu. Dari definisi ini dapat dirinci lebih lanjut pengertian sistem secara umum (Sutabri, 1998), yaitu sebagai berikut:

1. Setiap sistem terdiri dari unsur-unsur, unsurunsur suatu sistem terdiri dari subsistem yang lebih kecil, yang terdiri pula dari kelompok unsur yang membentuk subsistem tersebut.

2. Unsur-unsur tersebut merupakan bagian terpadau sistem yang bersangkutan. Unsurunsur sistem berhubungan erat satu dengan yang lain dan sifat serta kerja sama antarunsur sistem tersebut mempunyai bentuk tertentu.

3. Unsur sistem tersebut bekerja sama untuk mencapai tujuan sistem.

4. Suatu sistem merupakan bagian dari sistem yang lain yang lebih besar.

\section{E. Entity Relationship Diagram (ERD)}

Merupakan gambar atau diagram yang menunjukan informasi dibuat, disimpan, dan digunakan dalam sistem bisnis, dimana entitas biasanya menggambarkan jenis informasi yang sama yang digunakan untuk menghubungkan antar entitas yang sekaligus menunjukan hubungan antar data (Fatta, 2007).

\section{F. Diagram Context}

Diagram Context (top level) adalah bagian dari data flow diagram yang berfungsi memetakan model lingkungan yang dipresentasikan dengan lingkaran tunggal yang mewakili keseluruhan sistem (Fatta, 2007).

\section{G. Normalisasi}

Normalisasi merupakan salah satu cara pendekatan atau teknik yang digunakan dalam mengembangun desain lojik basis data relation dengan menerapkan sejumlah aturan dan criteria. Tujuan dari normalisasi adalah untuk menghasilkan struktur tabel yang normal dan baik. Syarat paling penting pada penyusunan sistem basis data adalah relasi dalam basis data harus normal. Oleh karena itu perlu dilakukan normalisasi terhadap basis data yang akan dibangun. Adapun syarat sebuah data dikatakan normal apabila telah sampai pada bentuk normal ketiga (Fatta, 2007).

\section{H. Rapid Aplication Development (RAD)}

Sebuah proses perkembangan perangkat lunak sekuensial linier yang menekankan siklus perkembangan dalam waktu yang singkat. RAD menggunakan metode iteratif (berulang) dalam mengembangkan sistem dimana working model (model bekerja) sistem dikonstruksikan di awal tahap pengembangan dengan tujuan menetapkan kebutuhan (requirement) pengguna dan selanjutnya disingkirkan. Dalam pengembangan sistem informasi normal, memerlukan waktu minimal 180 hari, namun dengan menggunakan metode RAD, sistem dapat diselesaikan dalam waktu 30-90 hari (Aji, 2007). Model RAD memiliki 3 tahapan sebagai berikut.

1. Rencana Kebutuhan (Requirement Planning): User dan analyst melakukan pertemuan untuk mengidentifikasi tujuan dari sistem dan kebutuhan informasi untuk mencapai tujuan. Pada tahap ini merupakan hal terpenting yaitu adanya keterlibatan dari kedua belah pihak.

2. Proses Desain Sistem (Design System): Pada tahap ini keaktifan user yang terlibat menentukan untuk mencapai tujuan karena pada proses ini melakukan proses desain dan melakukan perbaikan-perbaikan apabila masih terdapat ketidaksesuaian desain antara user dan analyst. Seorang user dapat langsung memberikan komentar apabila terdapat ketidaksesuaian pada desain, merancang sistem dengan mengacu pada dokumentasi kebutuhan user yang dibuat pada tahap sebelumnya. Keluaran dari tahapan ini adalah spesifikasi software yang meliputi organisasi 
sistem secara umum, struktur data dan yang lain.

3. Implementasi (Implementation): Tahapan ini adalahan tahapan programmer yang mengembangkan desain suatu program yang telah disetujui oleh user dan analyst. Sebelum diaplikasikan pada suatu organisasi terlebih dahulu dilakukan proses pengujian terhadap program tersebut apakah ada kesalahan atau tidak. Pada tahap ini user biasa memberikan tanggapan akan sistem yang sudah dibuat serta mendapat persetujuan mengenai sistem tersebut.

I. Siklus Hidup Pengembangan Sistem

Proses pengembangan sistem mempunyai beberapa tahapan mulai dari sistem itu direncanakan sampai dengan sistem tersebut diterapkan, dioperasikan, dan dipelihara (kendall, 2003). Adapun tahap-tahap yang harus dilaksanakan secara sistematis dalam pengembangan sistem informasi adalah sebagai berikut :

1. Kebijakkan dan perencanaan sistem (System planning).

a. Permintaan untuk studi suatu sistem (request for a system studi).

b. Pengamatan/investigasi awal (initial investigation)

c. Studi kelayakan (feasibility study).

2. Analisa sistem (System analysis)

a. Mendefenisikan kembali masalah (redefine the problem).

b. Memahami sistem yang ada (understand the existing system).

c. Menentukan kebutuhan pemakai (determine user requirement).

d. Model logika dari pemecahan yang direkomendasi (logical model of the recommended solution).

3. Desain sistem (System design)

a. Desain ouput (output design).

b. Desain Input (input design).

c. Desain file (file design).

4. Implementasi sistem(System implementation)

a. Pembangunan sistem (system building).

b. Pengetesan (Testing).

c. Instalasi/konversi (installation/conversion).

d. Operasi (operation).

e. Kaji ulang setelah implementasi (postimplementation review).

5. Perawatan (Maintenance)
a. Menggunakan sistem
b. Audit Sistem
c. Memelihara Sistem
d. Perawatan dan peningkatan-peningkatan

\section{Metodologi Penelitian}

\section{A. Teknik Pengumpulan Data}

Metodologi penelitian ini bertujuan untuk mendukung dalam memperoleh informasi yang dibutuhkan dalam rangka mencapai tujuan penelitian. Teknik pengumpulan data yang benar akan menghasilkan hasil perbandingan dari apa yang diteliti sebelumnya. Untuk mendapatkan data yang lengkap dan akurat, pada tahap analisis dilakukan metode pengambilan data yang meliputi:

1. Metode Pengamatan (Observasi)

Observasi atau pengamatan merupakan teknik pengumpulan data dengan cara meneliti secara cermat terhadap masalah-masalah yang sedang diteliti. disini penulis melakukan pengamatan bagaimana cara kerja sistem reservasi dan penyewaan kamar hotel pada Hotel Queen sehingga diperoleh data yang sesuai dan dijadikan salah satu acuan dalam penelitian.

2. Metode Studi Pustaka

Pengumpulan data yang penulis lakukan yaitu dengan cara mempelajari dan mengumpulkan sumber pustaka yang diperoleh dari berbagai buku-buku yang berkaitan dengan judul penelitian, hasil penelitian, skripsi, dan media lain sebagai referensi penulis dalam melakukan penelitian.

3. Metode Interview Atau Wawancara

Pengumpulan data dengan mengajukan pertanyaan-pertanyaan atau wawancara dengan para sumber atau pelaku yang terdapat dalam sistem. Dalam kasus ini pihak yang diwawancarai adalah para petugas receptionis dan pimpinan Hotel.

\section{Metode Dokumentasi}

Teknik pengumpulan data dengan cara mengumpulkan data yang diperoleh dari dokumen yang ada atau catatan - catatan yang tersimpan, baik itu berupa catatan transkrip, buku tamu, agenda, laporan, dimana penulis mempelajari dan mereview data pada dokumen milik perusahaan yang berhubungan dengan sistem reservasi dan penyewaan kamar hotel pada Hotel Queen dimana dokumen yang telah diperoleh kemudian dianalisis, dibandingkan dan dipadukan sehingga membentuk satu hasil kajian yang sistematis.

B. Tahapan Model RAD dalam Penelitian

Penelitian ini dilakukan dengan beberapa tahapan, agar mencapai tujuan yang direncanakan. Adapun tahapan model RAD dalam penelitian ini dijelaskan pada gambar 3.1: 


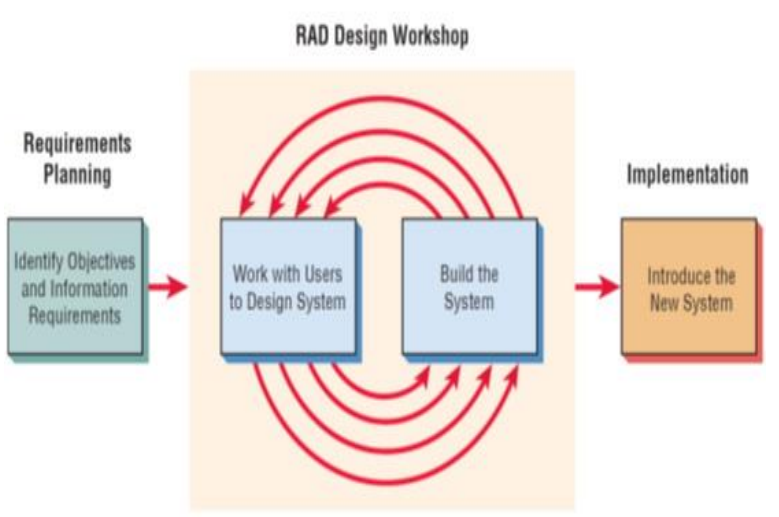

Gambar 3.1 Tahapan Model RAD (kendall, 2010)

a. Requirements Planning

Secara garis besar dalam fase Rencana Kebutuhan (Requirement Planning): User dan analyst melakukan pertemuan untuk mengidentifikasi tujuan dari sistem dan kebutuhan informasi untuk mencapai tujuan. Tahap Rencana Kebutuhan juga dilakukan pengumpulan dan analisis alat, bahan, sumber daya, biaya dan data Pada tahap ini merupakan hal terpenting yaitu adanya keterlibatan dari kedua belah pihak.

\section{b. RAD Design Workshop}

Secara garis besar pada tahap ini keaktifan user yang terlibat menentukan untuk mencapai tujuan karena pada proses ini melakukan proses desain dan melakukan perbaikanperbaikan apabila masih terdapat ketidaksesuaian desain antara user dan analis. Seorang user dapat langsung memberikan komentar apabila terdapat ketidaksesuaian pada desain, merancang sistem dengan mengacu pada dokumentasi kebutuhan user yang sudah dibuat pada tahap sebelumnya. Keluaran dari tahapan ini adalah spesifikasi software yang meliputi organisasi sistem secara umum, struktur data dan yang lain

\section{c. Implementation}

Tahap Implementasi merupakan tugas dari programmer meneruskan dalam bentuk coding melalui tinjauan pemrograman berdasarkan rancangan sistem yang telah dibuat oleh desainer sistem. Tinjauan pemrograman yang dipakai tergantung dari permintaan user.

\section{Hasil dan Pembahasan}

\section{A. Analisis Sistem}

Pada bagian ini akan dibahas bagaimana model rapid application development (RAD) dalam pengembangan sistem reservasi dan penyewaan kamar hotel. Karena sistem yang digunakan masih bersifat manual, sehingga sistem yang berjalan di Hotel Queen membutuhkan banyak waktu ketelitian dan membutuhkan sumber daya manusia yang benar - benar mampu mengolah data reservasi dan penyewaan kamar hotel, guna mengurangi terjadinya kesalahan dalam mengelola data. Dengan keadaan seperti ini maka dibuat dan dikembangkan suatu sistem reservasi dan penyewaan kamar hotel pada Hotel Queen agar dapat mempermudah dan mempercepat cara kerja seperti penginputan, pencarian data transaksi dan pembuatan laporan.

\section{B. Tujun Pembuatan Sistem}

Pembuatan sistem dapat berarti menyusun suatu sistem baru untuk membantu mengatasi permasalahan yang terjadi atau memperbaiki suatu sistem yang telah ada yang belum terkomputerisasi, karna adanya suatu permasalahan atau memenuhi instruksi yang diberikan oleh petugas hotel dan pengelola hotel. Tujuan pembuatan sistem menitik beratkan pada sistem reservasi dan penyewaan kamar hotel.

\section{Analisis Kebutuhan Sistem}

\section{Data Flow Diagram(DFD)}

Data flow diagram (DFD) merupakan gambaran grafis yang memperlihatkan aliran data dari sumbernya dalam objek kemudian melewati suatu proses yang mentransformasinya ke tujuan yang lain, yang ada pada objek lain. DFD memuat proses yang mentransformasi data, aliran data yang menggerakkan data, objek yang memproduksi serta mengkomsumsi data, serta data store yang menjadi tempat penyimpanan data.

\section{Diagram Konteks}

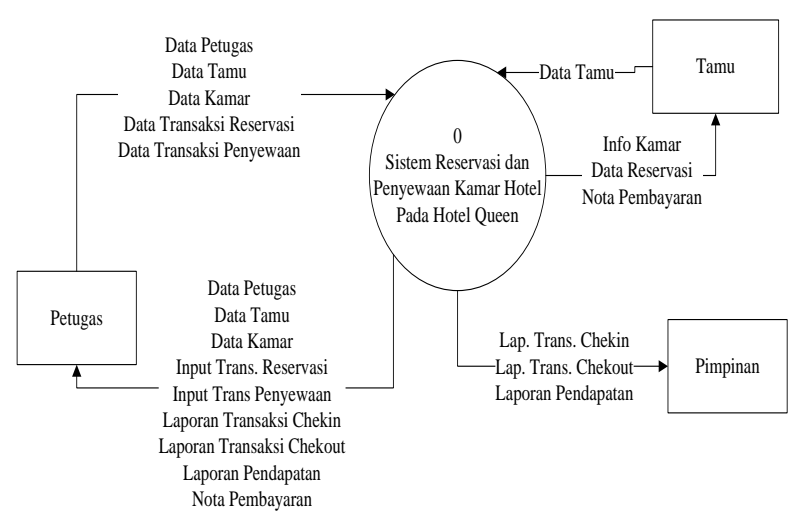

Gambar 3.2 Diagram Konteks 
2. Diagram Level 1

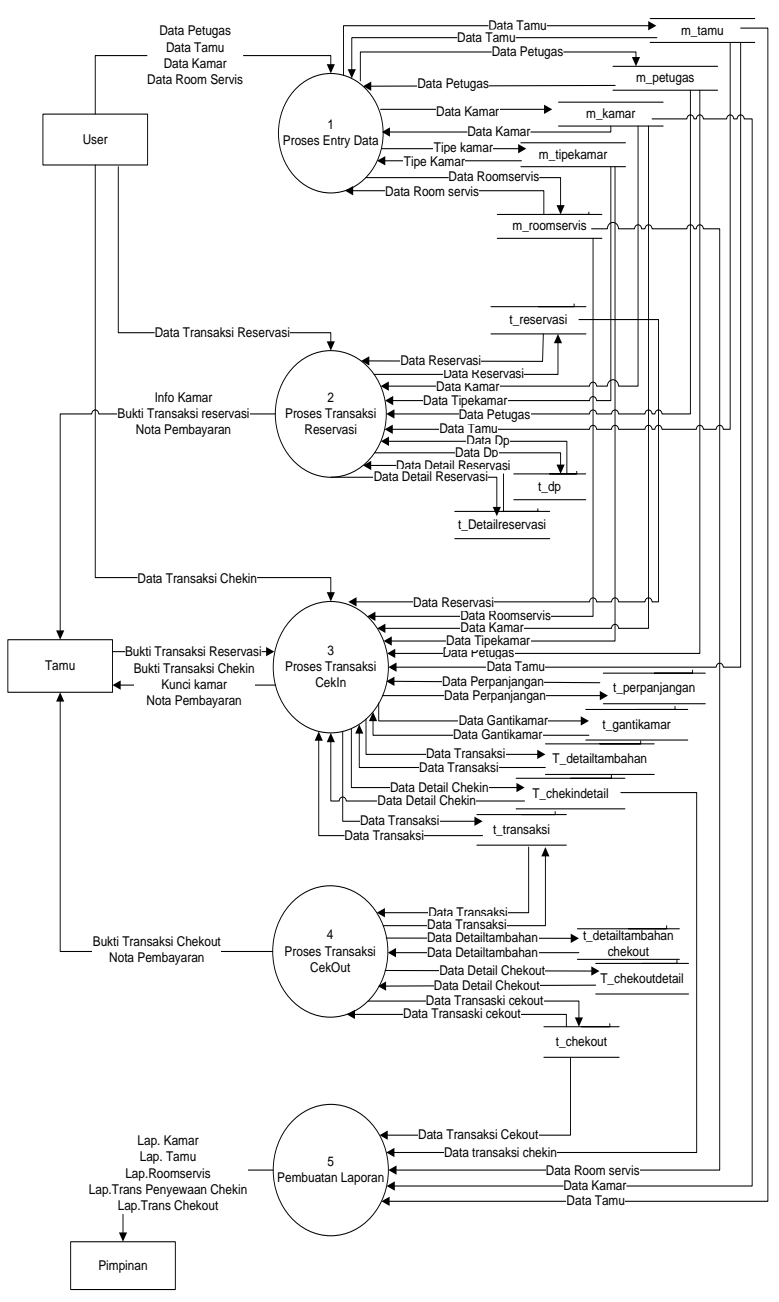

Gambar 3.3 Diagram Level 1

3. Diagram Level 2 Proses 1

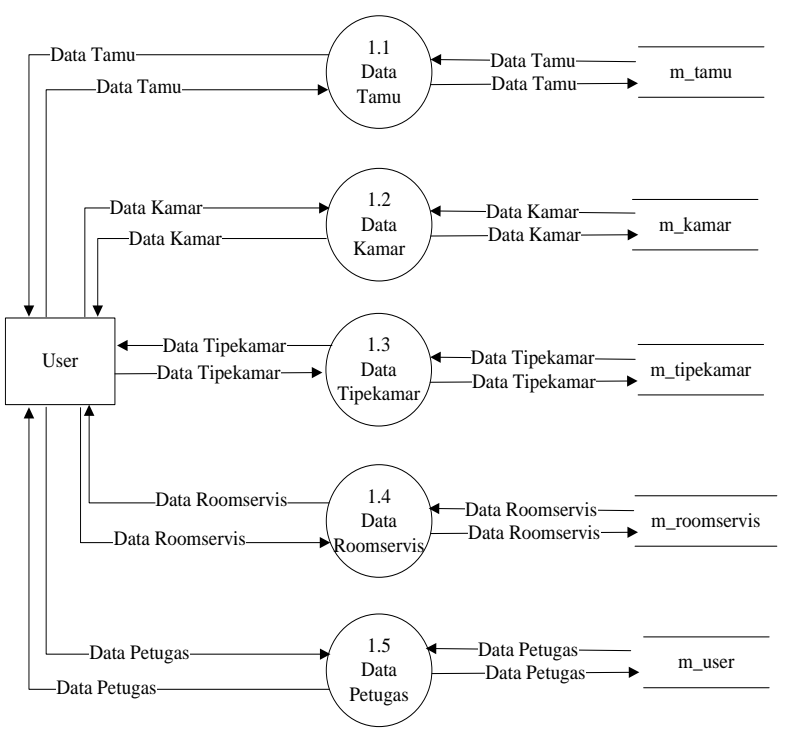

4. Diagram Level 2 Proses 2

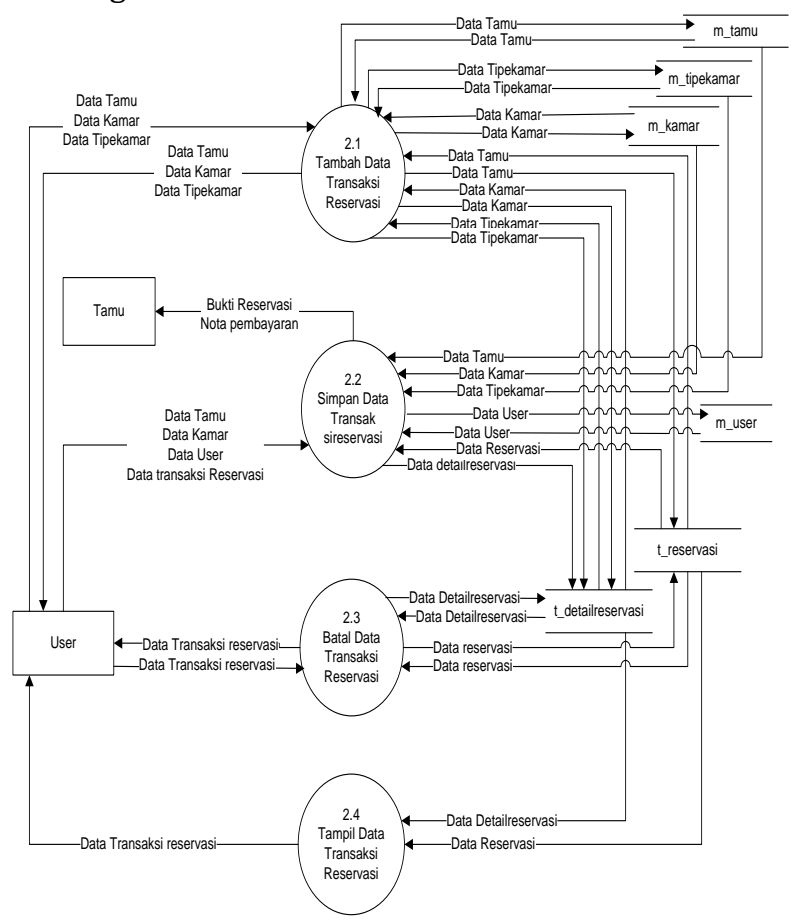

Gambar 3.5 Diagram Level 2 Proses 2

5. Diagram Level 2 Proses 3

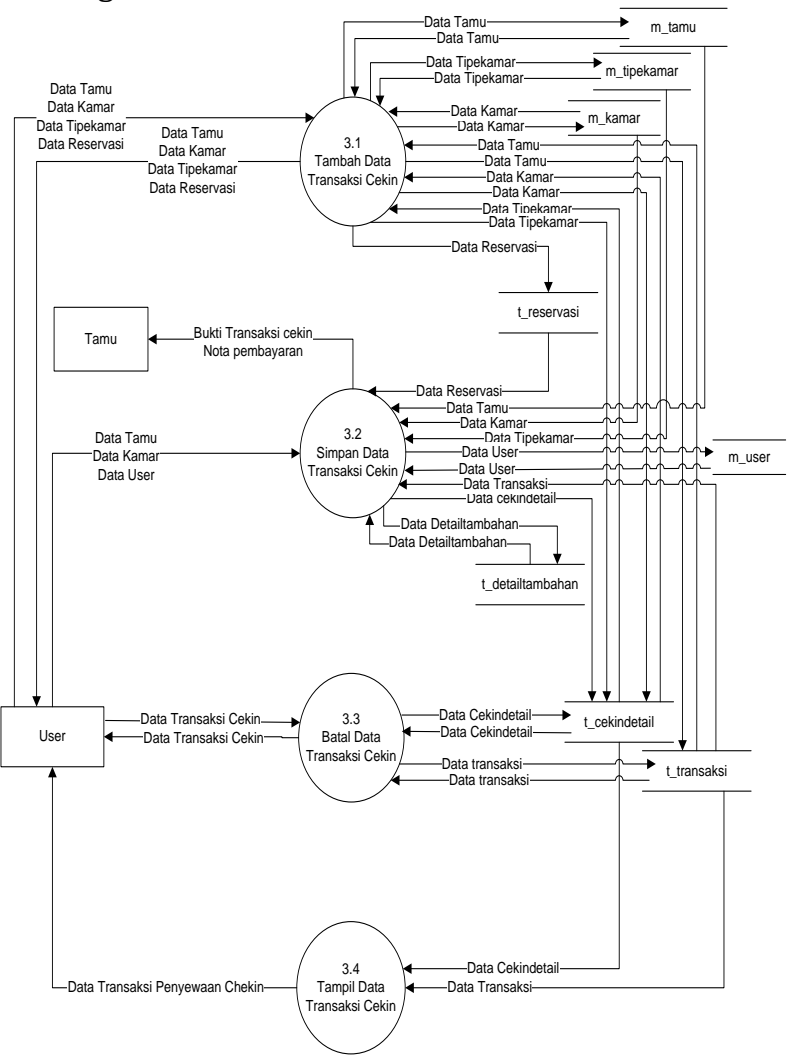

Gambar 3.6 Diagram Level 2 Proses 3

Gambar 3.4 Diagram Level 2 Proses 1 
6. Diagram Arus Data Level 2 Proses 4

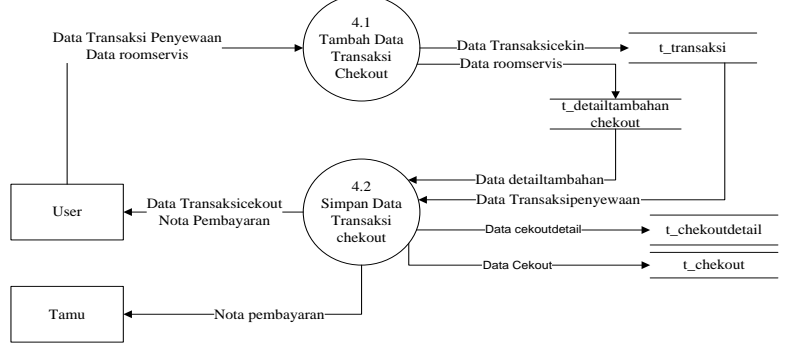

Gambar 3.7 Diagram Level 2 Proses 4

7. Diagram Arus Data Level 2 Proses 5

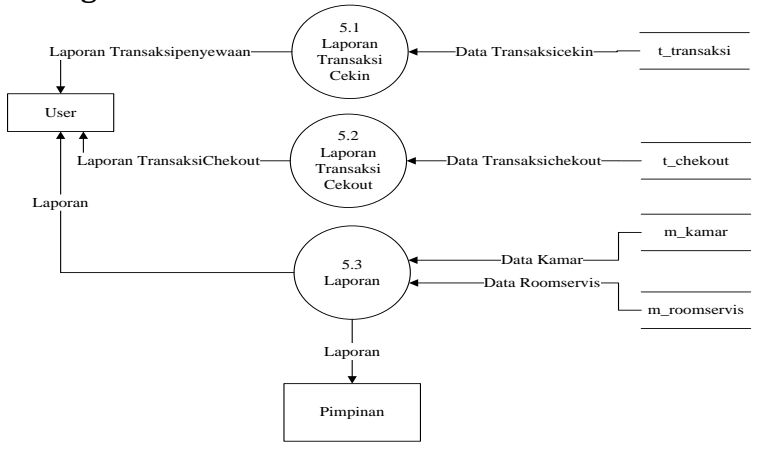

Gambar 3.8 Diagram Level 2 Proses 5

\section{Entity Relationship Diagram (ERD)}

Pada dasarnya adalah diagram yang memperlihatkan entitas-entitas yang terlibat dalam suatu sistem serta hubungan-hubungan (relasi) antar entitas tersebut.

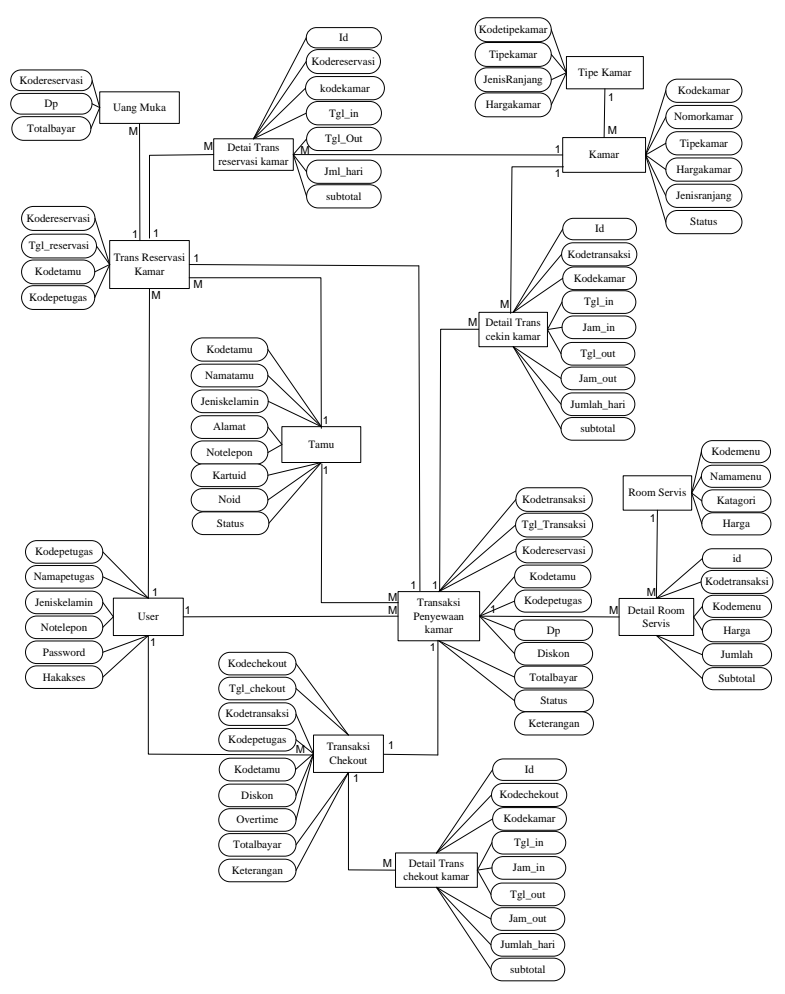

Gambar 3.9 Entity Relationship Diagram (ERD)

9. Arsitektur Program

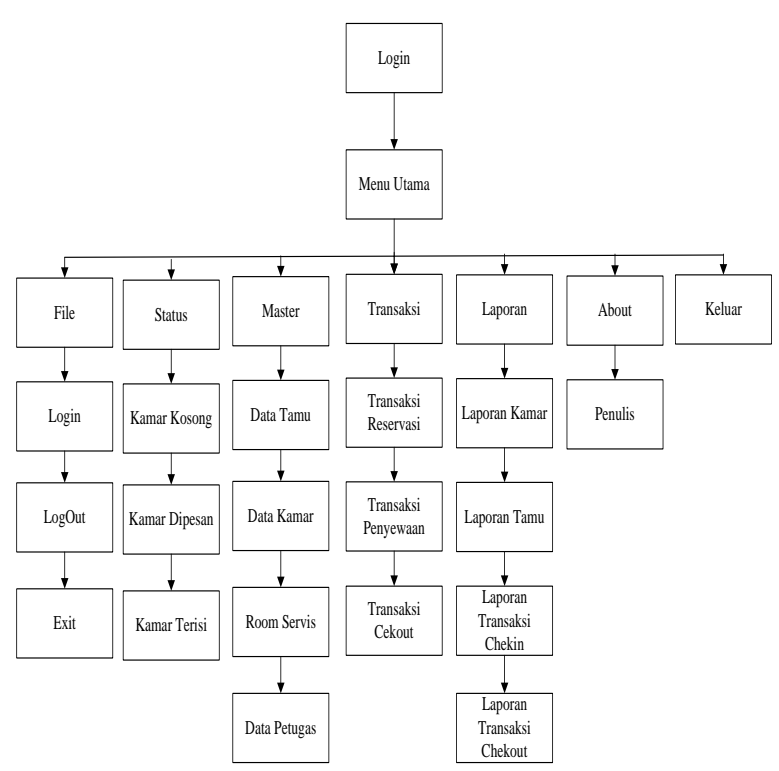

Gambar 3.10 Arsitektur Program

\section{Kesimpulan dan saran}

A. Kesimpulan

Berdasarkan kajian serta tinjauan teori yang dimiliki serta dari hasil analisis dan perancangan pengembangan sistem reservasi dan penyewaan kamar hotel menggunakan model rapid application development ( $R A D$ ), penyusun dapat menarik beberapa kesimpulan yaitu:

1. Sistem reservasi dan penyewaan kamar hotel yang dilakukan oleh Hotel Queen dirancang untuk mempermudah dan mempercepat dalam proses transaksi reservasi dan transaksi penyewaan kamar.

2. Penggunaan pencarian dalam transaksi dapat mempermudah dalam pencarian data transaksi reservasi dan data transaksi penyewaan kamar.

3. Dengan mengimplementasikan sistem ini dapat menjadi solusi dan alternatif dalam permasalahan yang sering terjadi seperti pencatatan data dan transaksi secara manual yang sering menimbulkan masalah.

4. Dengan adanya aplikasi ini akan memudahkan bagi petugas receptionis dan pimpinan Hotel Queen untuk mengakses data tamu, data kamar, data roomservis, data transaksi reservasi dan data transaksi penyewaan kamar.

B. Saran

Saran yang dapat disampaikan oleh penulis adalah agar penelitian berikutnya bisa mengembangkan sistem ini lebih baik lagi, 
sehingga kekurangan yang ada bisa dilengkap atau diperbaiki. Saran yang dapat digunakan sebagai bahan pertimbangannya adalah sebagai berikut:

1. Diharapakan nantinya dapat membuat kerjasama dengan pihak ketiga yaitu perusahaan penyedia layanan pembayaran tunai secara elektronik.

2. Hasil perhitungan laporan sebaiknya dilengkapi dengan menggunakan grafik, agar lebih memperlihat perbandingan yang terjadi

\section{Daftar Pustaka:}

(1) Al Fatta, H., 2007, Analisis Dan Perancangan Sistem Informasi. Andi. Yogyakarta.

(2) Ariani, Rimawati. 2011. "Komputerasi Sistem Pengolahan Data Tamu Pada Hotel Purnama I Berbasis Client Server (Studi Kasus: Hotel Purnama I)". Universitas Teknologi Yogyakarta, Yogyakarta.

(3) Arief, M. Rudyanto. 2006. "Pemrograman Basis Data Menggunakan Transact-SQL Dengan Microsoft SQL Server 2000". Andi Offset, Yogyakarta.

(4) Aswati, Safrian., Siagian, Yessica. 2016. Model Rapid Application Development Dalam Rancang Bangun Sistem Informasi Pemasaran Rumah (Studi Kasus : Perum Perumnas Cabang Medan. Seminar Nasional Sistem Informasi Indonesia, 1 Nopember 2016.

(5) Jogiyanto, H., 2010, Analisis dan Desain Sistem Informasi, Edisi III, Andi, Yogyakarta.

(6) Kadir, Abdul. 2003. "Pengenalan Sitem Informasi”. Andi Offset, Yogyakarta.

(7) Khairul Imtihan. "Perencanaan Strategi Sistem Informasi Pendidikan Pada Sekolah Tinggi Manajemen Informatika dan Komputer (STMIK) Lombok." Bianglala Informatika 3.2 (2015).

(8) Kusbiantoro, Pungud. 2006. "Komputerisasi Pengolahan Data Hotel Bali Asri Pacitan Dengan Microsoft Visual Basic 6.0". AMIKOM Yogyakarta, Yogyakarta.
(9) Kusdiawan, Wawan. 2010. “Cara Mudah dan Cepat Membuat Program Aplikasi Database Dengan Delphi". Gava Media, Yogyakarta.

(10) Kendall,Kenneth E. dan Kendall, Jullie E. System Analysis and Design, fifth Edition. Dialihbahasakan oleh Thamir Abdul Hafed Al-Hamdany, 2003, dalam buku analisis dan perancangan sistem, PT Prenhallindo, Jakarta.

(11) Nugroho, A., 2011, Perancangan Dan Implementasi Sistem Basis Data, Andi, Yogyakarta.

(12) Hodia, Maelani, and Khairul Imtihan-STMIK Lombok. "Perancangan Sistem Informasi Praktek Klinik Kebidanan (PKK) Pada Prodi DIII Kebidanan Stikes Qamarul Huda." IJNSIndonesian Journal on Networking and Security 6.3 (2017)

(13) Sardiarinto, dkk., 2015. Rancang Bangun Sistem Reservasi Hotel Menggunakan Metode Waterfall. Jurnal Bianglala Informatika, ISSN : 2338-9761, Vol.3 No.1, Maret 2015.

(14) Supriyanto, Aji, 2007,Pengantar Teknologi Informasi, Jakarta, Salemba Infotek.

(15) Susilawati, Sita, and Maulana Ashari. "Perancangan Jaringan Closed Circuit Television (CCTV) Berbasis Online Sebagai Monitoring Pada SDN 4 Praya." Jurnal Manajemen Informatika dan Sistem Informasi 1.1 (2018): 11-16.

(16) Sutabri, Tata. 1998. Sistem Informasi Manajemen. Andi Offset. Yogyakarta.

(17) Tandilian., Friska DL, 2015. Rancang Bangun Sistem Informasi Reservasi Hotel Berbasis Web dengan Framework Codeigniter (Studi Kasus CV. BSB Travel). Jurnal Sistem Dan Informatika Vol. 9, No. 2, Mei 2015.

(18) Zaen, M. Taufan Asri, Sunaryo Sunaryo, and Wijono Wijono. "Sistem Pendukung Keputusan untuk Investasi Perumahan Area Malang Menggunakan P Algoritma Bayesian." Jurnal EECCIS 8.1 (2014): 1318. 